\title{
New Extractive Spectrophotometric Determination of Flutamide in Pure and Pharmaceutical Formulations
}

\author{
Kanchugarakoppal S. RAngaPPa, ${ }^{* \dagger}$ Padmarajaiah NagaraJA, ${ }^{*}$ \\ and Kodagahalli Channaiah Srinivasa MURTHY** \\ *Department of Chemistry, University of Mysore, Manasagangotri, Mysore-570 006, India \\ **Department of Education in Science and Mathematics, Regional Institute of Education, \\ Manasagangotri, Mysore-570 006, India
}

(Received June 28, 1999; Accepted December 28, 1999)

Flutamide $^{1}$ (FLA) is widely used as an antiandrogen drug. It is also used for prosthetic cancer. It is chemically known as 2 methyl- $N$-[4-nitro-3-(trifluoromethyl)phenyl]propanamide. This drug and its primary hydroxy metabolite are nonsteroidal at the target cells in the secondary sex organs, but also decrease the metabolism of $\mathrm{C}-19$ steroids by the cytochrome P-450 system. ${ }^{2}$ This new drug is not yet included in U. S. P., B. P. or I. P. Zarapkar et al. ${ }^{3}$ first reported on the spectrophotometric determination of FLA utilizing the fact that it forms color when dissolved in hydrochloric acid. It exhibited maximum absorbance at $380 \mathrm{~nm}$ in the Beer's law concentration range of 2.5 to $15.0 \mu \mathrm{g} \mathrm{ml}^{-1}$. The reported analytical methods for the determination of FLA are chromatography, ${ }^{4}$ polarography, ${ }^{5}$ gas chromatography, ${ }^{6}$ and high-performance liquid chromatography. So far, there has been no chromogenic reagent reported for an estimation of FLA using spectrophotometry.

The authors have made some attempts in this direction, and succeeded to develop a new reagent, namely promethazine hydrochloride (PMH). It is noted that the reagent, itself, belongs to another class of drugs (tranquilisers). Nevertheless, the investigators have been able to develop an accurate and sensitive extractive method employing $\mathrm{PMH}$ in the presence of $\mathrm{N}$-bromosuccinimide for the determination of FLA in a bulk sample and its formulation.

\section{Experimental}

\section{Apparatus}

A JASCO Model UNIDEC-160 UV-Vis spectrophotometer with $1.0 \mathrm{~cm}$ matched cells was used for electronic spectral measurements.

\section{Reagents}

All of the chemicals and reagents used were of AR grade where otherwise not mentioned. Deionized water was used to prepare all solutions. It is noted that freshly prepared solutions were always employed.

Accurately weighed $50 \mathrm{mg}$ FLA was transferred to a $100 \mathrm{ml}$ beaker containing $1.0 \mathrm{ml}$ of concentrated hydrochloric acid,

$\dagger$ To whom correspondence should be addressed.

K. S. R. present address; Institute for Chemical Research, Kyoto University, Uji, Kyoto 611-0011, Japan.
$20.0 \mathrm{ml}$ of deionized water and $0.1 \mathrm{~g}$ of zinc metal. The solution was heated until the effervescence stopped and a redcolor solid was separated out. The solution was cooled to room temperature and filtered. The filtrate was diluted to $100 \mathrm{ml}$ in a volumetric flask with deionized water. A working standard solution of FLA containing $50 \mu \mathrm{g} \mathrm{ml}^{-1}$ was prepared by further dilution. An NBS solution $(0.02 \% \mathrm{w} / \mathrm{v})$ and a PMH (Sigma, USA) solution $(0.2 \% \mathrm{w} / \mathrm{v})$ were prepared in water.

\section{Recommended procedure}

First, $9.0 \mathrm{ml}$ of PMH and $3.0 \mathrm{ml}$ of NBS were added to various amounts $(0.25-150 \mu \mathrm{g})$ of FLA solutions (working standard) in a series of separating flasks, followed by the addition of $6.0 \mathrm{ml}$ of chloroform. The contents were shaken well and kept aside for 4.0 - $5.0 \mathrm{~min}$. After the separated organic phases were transferred to $50 \mathrm{ml}$ beakers, aqueous phases were once again extracted with $3.0 \mathrm{ml}$ of the same solvent. The successive extracted phases were mixed, dried over anhydrous sodium sulfate and transferred to $10.0 \mathrm{ml}$ standard flasks. The solutions were made up to the mark with the solvent. The absorbances of the extracts were measured at $505 \mathrm{~nm}$ against a freshly prepared reagent blank in the same manner, but without the drug. A calibration graph was constructed.

\section{For pharmaceutical formulations}

Twenty tablets were powdered and thoroughly mixed. A powdered tablet, equivalent to $50 \mathrm{mg}$, was taken and subjected to reduction using $1.0 \mathrm{ml}$ of concentrated hydrochloric acid and $0.1 \mathrm{~g}$ of zinc metal. The filtrate was made up to $100 \mathrm{ml}$, and an aliquot of this solution was diluted to obtain $50 \mu \mathrm{g} \mathrm{ml}^{-1}$. This solution was treated as described above for the determination of a pure sample of FLA.

\section{Results and Discussion}

\section{Absorption spectra of the colored product}

NBS oxidized the PMH to an unstable and unextractable lightclear red-colored product. A reddish-black product in an aqueous medium was obtained when FLA was added to the oxidized product of PMH. When it was extracted into chloroform it gave a stable red color at $\lambda_{\max }=505 \mathrm{~nm}$. The absorption spectra of the formed product and blank are graphically presented in Fig. 1. 


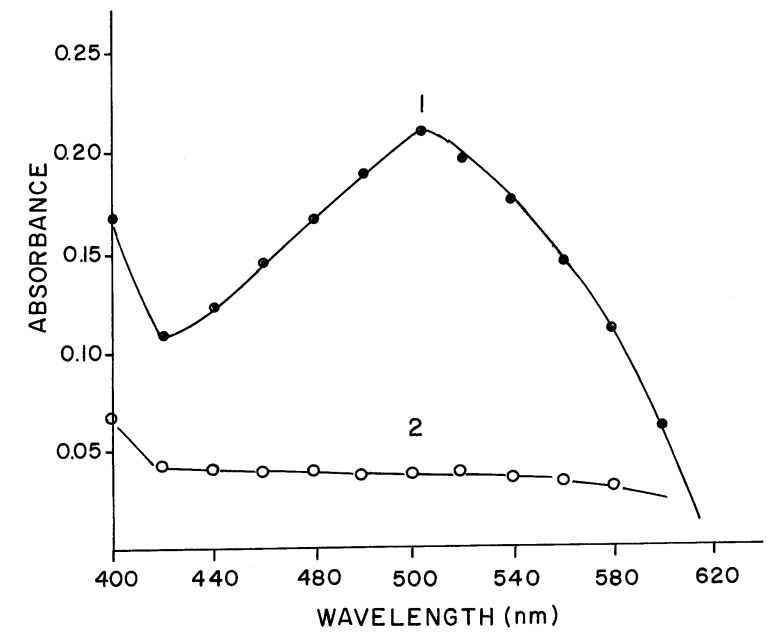

Fig. 1 Absorption spectra of FLA product (1) with reagent blank (2). FLA taken $7.5 \mu \mathrm{g} / \mathrm{ml}^{-1}$.

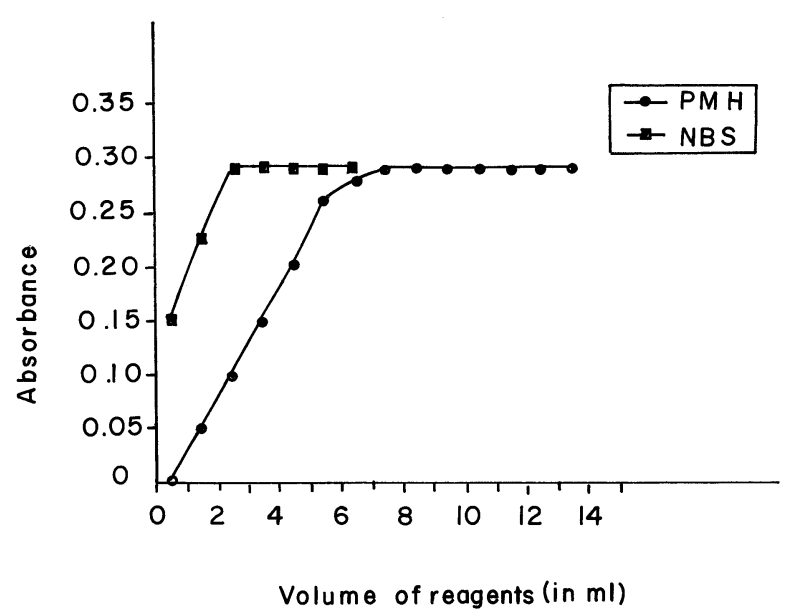

Fig. 2 The effect of reagents $(0.02 \% \mathrm{NBS}$ and $0.2 \% \mathrm{PMH})$ on color intensity final concentration of FLA is $10 \mu \mathrm{g} / \mathrm{ml}$.

\section{Optimum conditions for product formation}

In order to establish the optimum conditions necessary for a rapid and quantitative formation of the product with maximum stability and sensitivity, the investigators measured the absorbances of a series of solutions by varying one and fixing the other parameters at $505 \mathrm{~nm}$.

It was found that a $0.02 \%$ solution of NBS in the range 2.0 $4.0 \mathrm{ml}, 0.02 \%$ solution of PMH in the range $7.0-11.0 \mathrm{ml}$ were necessary to achieve the maximum color intensity of the product (Fig. 2). The color intensity decreased below the lower limit and above the upper limit, and a red-colored product was unstable. Therefore, $3.0 \mathrm{ml}$ of NBS and $9.0 \mathrm{ml}$ of PMH solutions were recommended for all measurements.

Carbon tetrachloride, benzene, 1,2-dichloromethane, dichloroethane and chloroform were tested as extractive solvents for the proposed reaction. Chloroform was preferred to others for its selective extraction of the colored product. It offers advantages, such as being economically cheaper and convenient, to be used as extractive solvent.

\section{Reaction mechanism}

Based on the Job's method of continuous variation, it was found that FLA interacted with the cited reagent in a ratio of

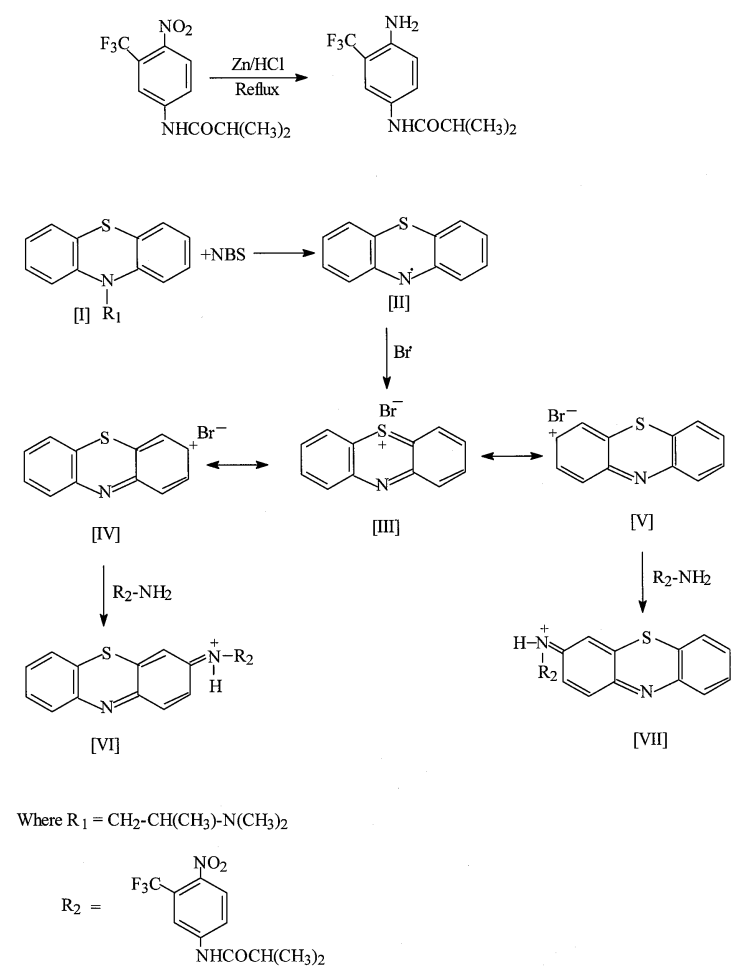

Scheme 1 Reaction mechanism.

1:1. This obviously supports the assumption that a Methylene Blue-like structure is formed. ${ }^{8-10}$ Accordingly, the following sequence of reactions could be suggested. The PMH (I) interacted first with NBS to form the phenothiazinyl free radical (II). Following this, II was oxidized to the PMH cation, which had the resonating forms III, IV and V. Thus, the lowest electron density on the PMH cation was found at positions C-3, C-7 and S-5, which permitted a nucleophilic attract at positions 3 or 7 by reduced FLA to form methylene blue-like dyestuff VI or VII (Scheme I).

\section{Effect of temperature on colored product}

The reaction between oxidized PMH (by NBS) and reduced FLA was found to be instantaneous. The effect of the temperature on the product was studied at different temperatures; it was found that the colored product was stable in the temperature range $0.0-35^{\circ} \mathrm{C}$. At higher temperatures the drug concentration was increased on prolonged heating due to the volatile nature of chloroform. As a result, the absorbance values of the colored product increased. However, the resultant products were stable for more than 4.0 days at $25 \pm 3^{\circ} \mathrm{C}$.

\section{Optical characteristics}

In order to test whether the red product formed obeys Beer's law or not, the absorbances of a series of solutions containing varying amounts of FLA were recorded against the reagent blank at $505 \mathrm{~nm}$. The Beer's law limits, molar absorptivity, specific absorptivity, Sandell's sensitivity and optimum range by photometric determination are summarized in Table 1 . The slope, the intercept and the correlation coefficient were evaluated by a least-squares regression analysis, and are also included in the same Table.

\section{Precision and accuracy}

The precision and accuracy of the proposed method were 
Table 1 Optical characteristics and precision of the flutamide

\begin{tabular}{lc}
\hline Optical characteristics and precision & Value \\
\hline Beer's law range $\left(\mu \mathrm{g} \mathrm{ml}^{-1}\right)$ & $0.25-15.0$ \\
Molar absorptivity $\left(1 \mathrm{~mol}^{-1} \mathrm{~cm}^{-1}\right)$ & $8.25 \times 10^{3}$ \\
Specific absorptivity $\left(\mathrm{ml} \mathrm{g}^{-1} \mathrm{~cm}^{-1}\right)$ & 0.0299 \\
Sandell's sensitivity $\left(\mu \mathrm{g} \mathrm{cm}^{-2}\right)$ & 0.0334 \\
Optimum range by photometric determination $\left(\mu \mathrm{g} \mathrm{ml}^{-1}\right)$ & $3.0-14.1$ \\
Regression equation $\left(y^{\mathrm{a}}\right)$ & \\
Slope $(a)$ & 0.0275 \\
Intercept $(b)$ & 0.0177 \\
Correlation coefficient $(r)$ & 0.9947 \\
$\%$ Relative standard deviation & \pm 1.39 \\
$\%$ Error & 0.49 \\
Color of the product & red \\
$\lambda_{\text {max }}(\mathrm{nm})$ & 505 \\
\hline
\end{tabular}

a. $y=a x+b$, where ' $x$ ' is the concentration of FLA $\left(\mu \mathrm{g} \mathrm{ml}^{-1}\right)$.

b. Calculated from 5 determinations.

c. Average of 3 determinations.

studied by analyzing solutions containing known amounts of FLA within the Beer's law limits. The percentage relative standard deviation was found to be less. The low values of the percentage errors are summarized. These values indicate the high precision and accuracy of the method.

\section{Interference studies}

The effect of the concomitants associated with the FLA in its pure form and its formulations were investigated using the developed method. This method does not suffer any interference from commonly associated excipients and additives in the preparation of tablets such as sucrose, lactose, dextrose, starch, talc, stearic acid and sodium alginate (Table 2).

\section{Application of method}

The applicability of the method for the assay of pharmaceutical preparations was examined. The results of assays of available tablets of FLA are summarized in Table 3. These results were reproducible. The results of the assay of tablets were crosschecked by the reported method. ${ }^{3}$

\section{Conclusion}

The results clearly indicate the utility of the proposed method for the analysis of FLA in pure and dosage forms. The redcolor of the product is very stable and thus rendering the method more practicable. The applicability of the method for the assay of FLA in pharmaceutical preparations has been well demonstrated. Further assaying authentic samples containing FLA as well as common additives and excipients tests the effect of interfering substances. Hence, this approach could be considered for the determination of FLA in quality control laboratories.
Table 2 Determination of FLA ${ }^{\mathrm{a}}$ in the presence of excipients

\begin{tabular}{lcr}
\hline \multicolumn{1}{c}{ Material } & Amount/mg & $\%$ Recovery FLA $\pm \%$ RSD $^{\mathrm{b}}$ \\
\hline Lactose & 20 & $99.4 \pm 1.21$ \\
Dextrose & 20 & $99.7 \pm 1.26$ \\
Sucrose & 20 & $101.0 \pm 0.98$ \\
Starch & 20 & $100.2 \pm 0.75$ \\
Talc & 20 & $99.8 \pm 0.96$ \\
Stearic acid & 10 & $98.9 \pm 0.94$ \\
Sodium alginate & 10 & $99.4 \pm 1.02$ \\
\hline
\end{tabular}

a. $5 \mu \mathrm{g} \mathrm{ml}^{-1}$ of FLA taken.

b. Average of five determination.

Table 3 Determination of FLA in pharmaceutical preparations

\begin{tabular}{lccc}
\hline \multirow{2}{*}{ Drug trade name } & Label claim(mg) & \multicolumn{2}{c}{$\%$ Recovery of FLA(mg) $\pm \%$ RSD $^{\mathrm{a}}$} \\
\cline { 3 - 4 } & & Proposed method & Reported method \\
\hline Cytomid $^{\mathrm{b}}$ & 250 & $249.95 \pm 0.59$ & $249.91 \pm 0.81$ \\
Drogenil $^{\mathrm{c}}$ & 250 & $250.01 \pm 0.68$ & $249.98 \pm 0.69$
\end{tabular}

a. Average of six determinations.

b. Marketed by Cipla Ltd.

c. Marketed by Fulford.

\section{Acknowledgement}

Prof. K. S. Rangappa thanks JSPS and Prof. K. Tamao for having given facilities to process this research manuscript.

\section{References}

1. “Merck Index", XI ed., 1989, 658.

2. "Remington's Pharmaceutical Sciences", 18th ed., 1996, Marck Publishing Co., Easton, 1152.

3. S. S. Zarapkar, C. D. Damle, and U. P. Halkar, Indian Drugs, 1996, 33, 193.

4. G. Ballon Ya, O. I. Lazebnaya, and I. S. Dukhovnaya, Khim-Farm. Zn., 1985, 19, 626.

5. A. Snycerski, J. Pharm. Biomed. Anal., 1989, 7, 1513.

6. D. Farthing, D. Sica, I. Fakhry, and L. Walters, Biomed. Chromatogr., 1994, 8, 251.

7. R. T. Sane, M. G. Gangrade, V. V. Bapat, and S. R. Sure, Indian Drugs, 1993, 30, 147.

8. P. Nagaraja, K. C. S. Murthy, and K. S. Rangappa, Indian J. Pharm. Sci., 1999, 61, 105.

9. M. E. Kl-Kommes and K. M. Emara, Analyst, 1998, 113, 1267.

10. S. R. El-Shabouri, A. F. Youssef, F. A. Mohamed, and A. M. I. Ragen, J. Assoc. Off. Anal. Chem., 1986, 169, 821. 